\title{
DESEMPENHO FISIOLÓGICO DE SEMENTES DE ALGODOEIRO TRATADAS COM TIAMETOXAM ${ }^{1}$
}

\author{
LUCIANA REGINA LAUXEN², FRANCISCO AMARAL VILLELA ${ }^{3}$, RODRIGO CASTRO SOARES ${ }^{4}$
}

\begin{abstract}
RESUMO - Novos produtos para incorporação às sementes vêm sendo disponibilizados anualmente. Bioativadores, como o inseticida tiametoxam, são utilizados para aumentar o potencial produtivo das plantas, através de modificações no metabolismo vegetal. Objetivou-se neste trabalho avaliar os efeitos do tiametoxam na qualidade fisiológica de sementes de algodoeiro, particularmente no crescimento radicular de plântulas de algodoeiro e estabelecer concentrações do produto para prétratamento de sementes. Foram utilizados três lotes de sementes de algodoeiro, cultivar CD 408, tratadas com Cruiser ${ }^{\circledR} 350$ FS contendo 35 gramas de ingrediente ativo (i.a.) de tiametoxam por litro, sendo, submetidas a seis doses: 0, 2, 4, 6, 8 e $10 \mathrm{~mL}$ de Cruiser ${ }^{\circledR} 350 \mathrm{FS} / \mathrm{kg}$ de semente. As avaliações utilizadas foram: germinação, primeira contagem de germinação, envelhecimento acelerado, comprimento e massa de matéria seca do sistema radicular, índice de velocidade de emergência e emergência final de plântulas. $\mathrm{O}$ tratamento de sementes de algodoeiro com tiametoxam favorece positivamente a qualidade fisiológica das sementes, e as doses de 5,0 a 7,0 mL de Cruiser® $350 \mathrm{FS} /$ $\mathrm{kg}$ de semente mostram-se mais eficientes em melhorar o desempenho fisiológico das sementes de algodoeiro.
\end{abstract}

Termos para indexação: Gossypium hirsutum, bioativador, vigor, qualidade fisiológica.

\section{PHYSIOLOGICAL PERFORMANCE OF COTTON SEEDS TREATED WITH THIAMETOXAM}

\begin{abstract}
The introduction of new seed treatment products is increasing and bioactivators, such as the insecticide thiametoxam, are used to increase plant yield potential by modifying metabolism. The objective of this study was to evaluate the effects of thiametoxam on the physiological quality of cotton seeds, particularly on seedling root growth, and establish product concentrations for seed pre-treatment. Three seed lots of the cultivar CD 408 were evaluated which had been treated with six dosages of Cruiser ${ }^{\circledR} 350$ FS containing 35 g/L A.I. of thiametoxam, at 0, 2, 4, 6, 8 and $10 \mathrm{~mL}$ per kg of seeds. Parameters measured included: standard germination test, germination first count, accelerated ageing, root dry matter and length, emergence velocity rate and final seedling emergence. Cotton seeds treated with thiametoxam demonstrated improved physiological quality of the seeds and the dosages of 5.0 to $7.0 \mathrm{~mL}$ of the Cruiser ${ }^{\circledR} 350 \mathrm{FS} / \mathrm{kg}$ of seeds were more efficient in improving the physiological performance of cotton seeds.
\end{abstract}

Index terms: Gossypium hirsutum, bioactivator, vigor, physiological quality.

\footnotetext{
${ }^{1}$ Submetido em 24/08/2009. Aceito para publicação em 20/04/2010. Parte da Dissertação do Mestrado da primeira autora apresentada a UFPel.
}

${ }^{2}$ Eng. Agr., Doutoranda do PPG em Ciência e Tecnologia de Sementes, UFPel/FAEM, Pelotas-RS. E-mail: lucianalauxen@yahoo.com.br
${ }^{3}$ Eng. Agrigola, Dr. Prof. Titular, Depto de Ciência e tecnologia de Sementes, FAEM/UFPel, C.P 354, Cep: 96010-900, Pelotas-RS.

${ }^{4}$ Eng. Agr. Msc. do PPG em Ciência e Tecnologia de Sementes, UFPel/ FAEM, Pelotas-RS. 


\section{INTRODUÇÃO}

O algodão é uma das plantas mais cultivadas pelo homem, tendo em vista sua fibra, produto de consumo generalizado em todo o mundo e ainda, o óleo, a farinha da torta, o línter e a casca, todos extraídos da semente ou caroço (Zanqueta et al., 2001).

A cadeia produtiva do algodão é uma das principais no agronegócio brasileiro e mundial. No Brasil é de grande importância sócio-econômica, gerando milhares de empregos diretos e indiretos. O Estado do Mato Grosso apresenta-se como principal produtor desta malvácea, porém o cultivo do algodão tem sido registrado em mais de quinze estados, sendo o Estado da Bahia o maior produtor nordestino (Medeiros Filho et al., 2006).

Um dos fatores limitantes para o sucesso da cultura do algodoeiro tem sido a dificuldade de obter sementes com qualidade física, fisiológica e sanitária capazes de proporcionar o estabelecimento dessa cultura com população ideal e com plântulas uniformes e vigorosas. Porém, é um dos aspectos mais importantes para a obtenção de elevadas produtividades e com qualidade intrínseca da fibra requerida pela moderna indústria têxtil nacional e internacional. A instabilidade climática e o emprego de sementes de baixa qualidade são os fatores determinantes da baixa produtividade da cultura do algodão (Kikuti et al., 2002).

Um dos principais fatores que tem contribuído para a baixa produtividade do algodoeiro no Brasil é a utilização de sementes de baixa qualidade fisiológica, com reflexos na desuniformidade do estande após a semeadura (Ribeiro et al., 2002).

A semente é um insumo de grande relevância no processo produtivo e sua qualidade é indispensável à implantação de lavouras conduzidas tecnicamente. A qualidade de um lote de sementes compreende uma série de características ou de atributos que determinam o seu valor para a semeadura; dentre os mais relevantes, são considerados os de natureza genética, fisiológica e sanitária (Marcos Filho et al., 1994).

O poder germinativo das sementes de algodoeiro pode ser afetado por condições ambientais, bem como pelo desenvolvimento de fungos patogênicos, devido à exposição do fruto no campo (Rodrigues Filho, 1979), existindo uma relação estreita entre incidência e tipo de patógenos presentes na semente e sua qualidade fisiológica.

Dos fatores do ambiente que mais interferem na germinação das sementes, a temperatura e principalmente a umidade são os mais importantes, podendo causar deterioração das sementes (Dutra e Castro, 1997).

Os agricultores têm exigido, cada vez mais, sementes de alta qualidade, que possibilitem uma emergência mais rápida e um estande uniforme no campo. Para isso, o uso de tratamentos de pré-semeadura vem sendo estudados como alternativa (Kikuti et al., 2002).

O tratamento de sementes é uma tecnologia recomendada pela pesquisa, diminuindo falhas na germinação, mas os fungicidas e inseticidas atualmente disponíveis para tratamento de sementes de algodoeiro têm mostrado eficiência variável no controle de fungos causadores de tombamento de plântulas (Goulart, 1998).

Dentre as modernas técnicas agrícolas, a utilização de bioativadores visando o aumento do potencial produtivo das plantas, é uma prática de uso crescente na agricultura e amplamente difundida nos países altamente tecnificados (Serciloto, 2002).

No Brasil, o uso de bioativadores começa a ser explorado e experimentos têm demonstrado que essas substâncias podem aumentar significativamente a produtividade e, principalmente, a qualidade, onde se tem observado incrementos significativos na quantidade de frutos maiores (Serciloto, 2002).

Os bioativadores são substâncias naturais de origem vegetal que possuem ações semelhantes aos principais reguladores vegetais, visando o crescimento e o desenvolvimento da planta. Proporcionam um melhor equilíbrio fisiológico, favorecendo uma maior aproximação ao potencial genético da cultura (Castro et al., 2008).

Aplicados às plantas, os bioativadores causam modificação ou alteração de processos metabólicos e fisiológicos específicos, tais como: aumento da divisão e alongamento celular; estímulo da síntese de clorofila; estímulo da fotossíntese; diferenciação das gemas florais; aumento da vida útil das plantas, amenizando os efeitos das condições climáticas adversas bem como aumentando a absorção de nutrientes; aumento na fixação (pegamento) e no tamanho dos frutos (Cataneo et al., 2006).

A ação dos bioativadores, além das várias funções, tem interação com a nutrição de plantas, aumentando a eficiência na absorção, transporte e assimilação dos nutrientes (Castro e Vieira, 2003).

O tiametoxam, inseticida sistêmico do grupo neonicotinóide, tem efeito bioativador, atuando na expressão dos genes responsáveis pela síntese e ativação de enzimas metabólicas, relacionadas ao crescimento da planta, alterando a produção de aminoácidos precursores de hormônios vegetais (Castro, 2006a). Com a maior produção de hormônios, a 
planta apresenta maior vigor, germinação e desenvolvimento de raízes (Castro, 2006b). Com um maior número de raízes, aumenta a absorção e a resistência dos estômatos da planta à perda de água, o que beneficia o metabolismo e aumenta a resistência aos estresses (Castro et al., 2005).

Os inseticidas e fungicidas normalmente são avaliados quanto à eficiência no controle de pragas e doenças. Todavia, alguns podem provocar efeitos ainda pouco conhecidos, capazes de modificar o metabolismo e a morfologia vegetal (Pereira, 2007). Na literatura encontram-se trabalhos com inseticidas demonstrando alterações fisiológicas e morfológicas em plantas, como o aldicarb (Reddy et al., 1990), o carbofuran (Freitas et al., 2000) e o tiametoxam (Calafiori e Barbieri, 2001).

O composto tiametoxam, utilizado no início do cultivo, funciona como um bioativador, aumentando a produção de hormônios que regulam o desenvolvimento da planta (Cataneo et al., 2006). Testes com soja apontaram efeitos positivos do inseticida no crescimento, na área foliar e na proliferação de raízes, o que aumentou a absorção de água e de sais minerais (Castro, 2006b). Biotestes com tomateiro Micro-Tom e seus mutantes mostraram que a substância atua indiretamente na síntese de hormônios vegetais endógenos, diferenciandose dos biorreguladores, que possuem ação direta sobre as plantas (Serciloto, 2002).

Novos produtos para a incorporação de aditivos às sementes, como o tiametoxam estão disponíveis no mercado. No entanto, pouco é conhecido sobre a efetiva influência desses produtos à base de hormônios, micronutrientes, aminoácidos e vitaminas na qualidade fisiológica das sementes e na produtividade das culturas.

Neste trabalho objetivou-se avaliar os efeitos do tiametoxam na qualidade fisiológica de sementes de algodoeiro, particularmente no crescimento radicular das plântulas e estabelecer concentrações do produto para prétratamento de sementes.

\section{MATERIAL E MÉTODOS}

Os ensaios foram conduzidos no laboratório de sementes e em casa de vegetação do departamento de fitotecnia da Faculdade de Agronomia Eliseu Maciel (FAEM) da Universidade Federal de Pelotas (UFPel).

Foram utilizadas sementes de algodoeiro, cultivar CD 408, representada por três lotes. As sementes foram tratadas com Cruiser ${ }^{\circledR} 350 \mathrm{FS}$ contendo 35 gramas de ingrediente ativo (g.i.a.) de tiametoxam por litro. As sementes foram submetidas a seis doses: Tratamento 1 - sementes não tratadas; Tratamento
2-2 $\mathrm{mL}$ de Cruiser ${ }^{\circledR} 350 \mathrm{FS} / \mathrm{kg}$ de semente; Tratamento $3-4$ $\mathrm{mL}$ de Cruiser ${ }^{\circledR} 350 \mathrm{FS} / \mathrm{kg}$ de semente; Tratamento $4-6 \mathrm{~mL}$ de Cruiser ${ }^{\circledR} 350 \mathrm{FS} / \mathrm{kg}$ de semente; Tratamento $5-8 \mathrm{~mL}$ de Cruiser ${ }^{\circledR} 350 \mathrm{FS} / \mathrm{kg}$ de semente e Tratamento $6-10 \mathrm{~mL}$ de Cruiser ${ }^{\circledR} 350 \mathrm{FS} / \mathrm{kg}$ de semente.

Os tratamentos com 2, 4, 6, 8 e $10 \mathrm{~mL}$ de Cruiser ${ }^{\circledR} 350$ $\mathrm{FS} / \mathrm{kg}$ de semente correspondem a 0,$07 ; 0,14 ; 0,21 ; 0,28 \mathrm{e}$ 0,35 g.i.a. de tiametoxam por litro respectivamente.

A calda (produto + água destilada) foi aplicada, com o auxílio de uma pipeta graduada, no fundo de um saco plástico transparente e espalhada pelas paredes do saco até uma altura de $15 \mathrm{~cm}$. As sementes foram tratadas inicialmente com solução de hipoclorito $10 \%$ durante 2 minutos, e posteriormente foram colocadas no saco plástico juntamente com a calda. Os sacos contendo as sementes mais a calda foram inflados com ar e agitados vigorosamente durante 2 minutos, visando uniformizar a distribuição do tratamento sobre toda a massa de sementes. $\mathrm{O}$ volume de calda utilizado foi de 1,31/100 kg de sementes.

Os efeitos dos tratamentos foram determinados mediante as seguintes avaliações:

Teste de germinação: foram utilizadas quatro repetições com quatro subamostras de 50 sementes, totalizando 800 sementes para cada tratamento. As sementes foram semeadas em rolos de papel "Germitest", umedecido com água destilada, na proporção de 2,5 vezes o peso do papel seco e foram mantidas em germinador a $25^{\circ} \mathrm{C}$. As avaliações foram realizadas segundo as Regras para Análise de Sementes (Brasil, 1992). A contagem de plântulas normais foi realizada aos 4 e 12 dias após a instalação do teste e os resultados expressos em porcentagem de plântulas normais.

Primeira contagem de germinação: realizada conjuntamente com o teste de germinação, consistiu no registro da porcentagem de plântulas normais verificada na primeira contagem do teste de germinação, realizada no quarto dia após a semeadura, seguindo as Regras para Análise de Sementes (Brasil, 1992), e os resultados expressos em porcentagem de plântulas normais.

Comprimento do sistema radicular: foram utilizadas oito subamostras de 15 plântulas para cada tratamento. As sementes foram semeadas em rolos de papel "Germitest", umedecido com água destilada, na proporção de 2,5 vezes o peso seco do papel, e mantidas em germinador a $25^{\circ} \mathrm{C}$. O comprimento do sistema radicular foi medido aos 7 dias após a semeadura e os resultados expressos em cm por plântula.

Matéria seca do sistema radicular: foram utilizadas as plântulas oriundas da avaliação de comprimento do sistema radicular, sendo utilizado o mesmo numero de plântulas e de 
repetições. O sistema radicular das plântulas foi retirado com o auxílio de um bisturi e mantido em estufa termoelétrica de circulação forçada a $70{ }^{\circ} \mathrm{C}$, durante 24 horas. Após esse período, as amostras foram colocadas para esfriar em dessecador e tiveram sua massa determinada em balança com precisão de $0,001 \mathrm{~g}$, sendo os resultados expressos em miligramas por planta.

Envelhecimento acelerado: o teste foi conduzido pelo método de caixas plásticas (Mcdonald Jr. \& Phaneendranath, 1978), utilizando-se sementes distribuídas em uma camada simples sobre a tela interna e no fundo contendo $40 \mathrm{~mL}$ de água destilada. As caixas contendo as sementes foram mantidas a $42{ }^{\circ} \mathrm{C}$ durante 60 horas, em incubadora tipo BOD, de acordo com recomendações de Laposta (1991). Decorrido o período de envelhecimento, as sementes foram semeadas em quatro repetições com quatro subamostras de 50 sementes para cada tratamento, e mantidas em um germinador de câmara a $25^{\circ} \mathrm{C}$. Os rolos de papel germitest foram umedecidos com quantidade de água equivalente a 2,5 vezes o peso do papel seco. Determinou-se a porcentagem de plântulas normais no quarto dia.

Índice de velocidade de emergência (IVE): foram utilizadas quatro repetições com 25 sementes para cada tratamento. As sementes foram semeadas em canteiros em casa de vegetação, empregando terra como substrato. Foram realizadas contagens diárias das plântulas emergidas do solo, até 21 dias. O índice de velocidade de emergência foi calculado usando a fórmula proposta por Maguire (1962).

Emergência final: foram utilizadas as plântulas oriundas da avaliação do índice de velocidade de emergência. Desta maneira, o número final de plântulas emergidas aos 21 dias após a semeadura foi transformado em percentagem e considerado emergência final.

$\mathrm{O}$ delineamento experimental foi inteiramente casualizado, em fatorial $3 \times 6$ (lotes $\mathrm{x}$ doses do produto), com quatro repetições. Os efeitos das doses foram analisados por regressão polinomial. Os dados de porcentagem foram transformados em arco seno.

\section{RESULTADOS E DISCUSSÃO}

Sementes de algodão, tratadas com tiametoxam tiveram desempenho superior, em todos os atributos estudados, em relação aos valores obtidos no tratamento 1 (sem aplicação de tiametoxam), variando apenas a amplitude desta diferença em função da dose utilizada em cada tratamento.

Para a porcentagem de germinação, verifica-se que, a partir da dose zero, houve aumento na porcentagem de plântulas normais nos tratamentos contendo tiametoxam, independentemente da dose utilizada (Figura 1).

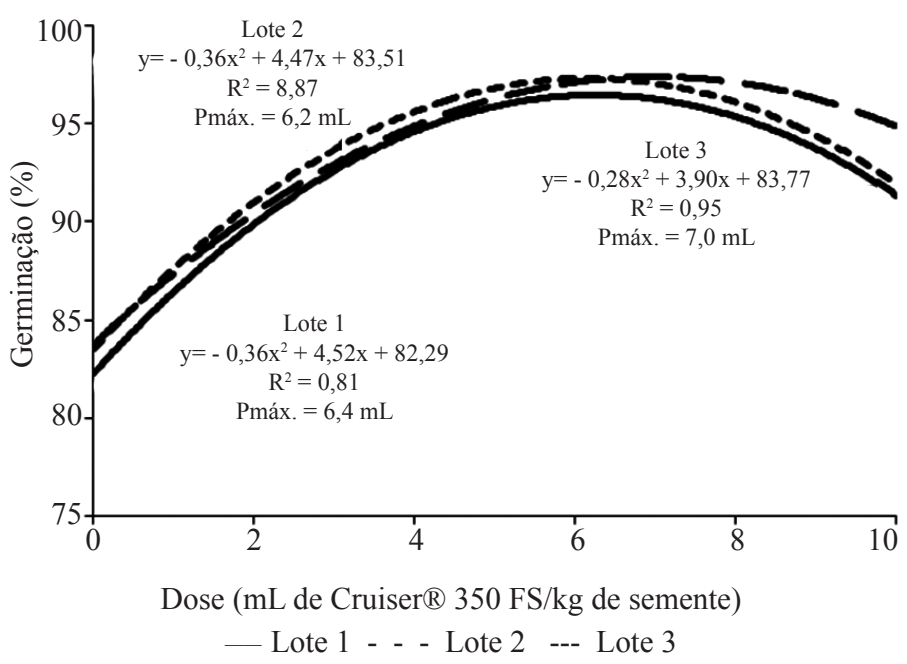

FIGURA 1. Germinação (\%) de três lotes de sementes de algodão, cultivar CD 408, em função da dose de Cruiser ${ }^{\circledR} 350$ FS contendo 35 gramas de tiametoxam por litro.

A germinação aumentou até o máximo atingido entre as doses de 6,2 a 7,0 $\mathrm{mL}$ de Cruiser ${ }^{\circledR} 350 \mathrm{FS} / \mathrm{kg}$ de semente, e a seguir decresceu com a elevação da dose do produto, com intensidade variável conforme o lote.

Vale destacar que empregando doses de 6,2 a $7,0 \mathrm{~mL}$ do Cruiser ${ }^{\circledR} 350 \mathrm{FS} / \mathrm{kg}$ de semente, conforme o lote houve aumento na expressão da germinação de 12 a 14 pontos percentuais relativamente às sementes não tratadas.

Analisando a Figura 2, pode-se observar um aumento progressivo da porcentagem de plântulas normais obtidas na primeira contagem de germinação, chegando a um ponto máximo, dependendo do lote, quando a dose alcança 6,4 a 7,2 mL de Cruiser ${ }^{\circledR} 350 \mathrm{FS} / \mathrm{kg}$ de semente. A partir desse ponto, começa a apresentar diminuição.

Atualmente, encontra-se estabelecido na literatura (Serciloto, 2002) que aplicação exógena de certos bioativadores em sementes promove sua germinação, estimulando a biossíntese e ação de enzimas hidrolíticas necessárias a este processo metabólico.

Os resultados encontrados neste trabalho corroboram os obtidos por Castro (2006 a), trabalhando com soja, ao afirmar que sementes tratadas com tiametoxam tiveram sua germinação acelerada por estimularem a atividade de enzimas, além de terem apresentado estande e emergência 
mais uniforme e melhor arranque inicial. Também em sementes de soja, Cataneo et al. (2006) observaram que o tiametoxam acelera a germinação, induz maior desenvolvimento do eixo embrionário, minimizando os efeitos negativos em situações de estresse.

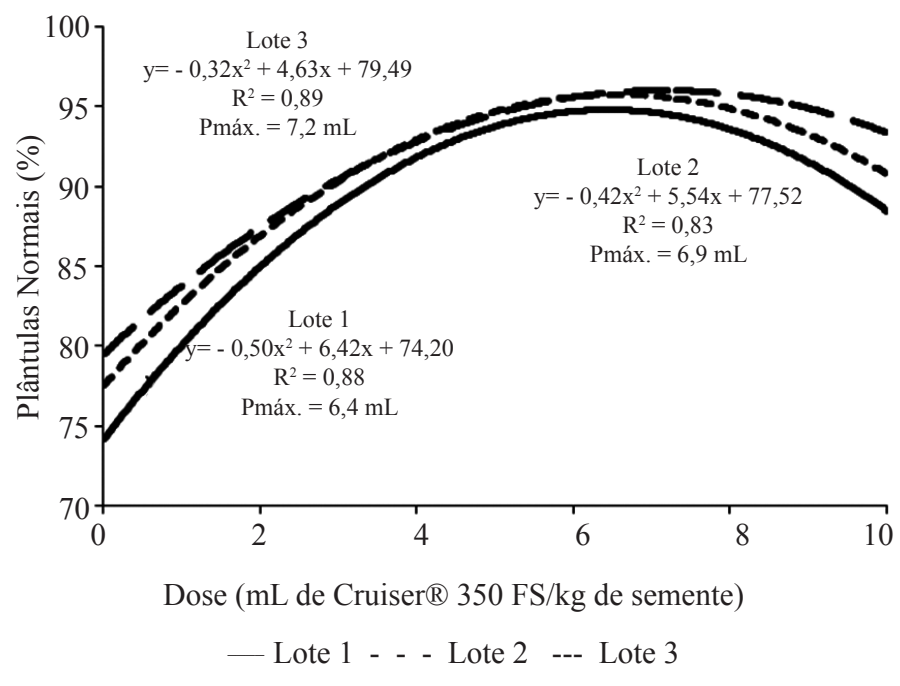

FIGURA 2. Plântulas normais (\%) obtidas na primeira contagem do teste de germinação de três lotes de sementes de algodão, cultivar CD 408, em função da dose de Cruiser ${ }^{\circledR} 350$ FS contendo 35 gramas de tiametoxam por litro

Conforme mostra a Figura 3, para o teste de envelhecimento acelerado houve uma separação mais visível entre os lotes, tendo os lotes 1 e 2 curvas com tendências similares, porém com valores distintos. Todavia, o lote 3 apresenta uma curva com concavidade mais acentuada em relação às outras duas, com variações mais expressivas na porcentagem de plântulas normais. Assim como nos testes anteriores, pode-se perceber que a partir da dose zero, a curva possui tendência crescente, chegando a um ponto máximo, quando as doses alcançam 4,5 a 5,3 $\mathrm{mL}$ de Cruiser $350 \mathrm{FS} / \mathrm{kg}$ de semente, conforme o lote. Após atingir esse ponto, os valores começam a apresentar diminuição de acordo com o incremento da dose.

A utilização de doses iguais a 4,5; 5,3 e $4,9 \mathrm{~mL}$ de Cruiser ${ }^{\circledR} 350 \mathrm{FS} / \mathrm{kg}$ de semente, para os lotes 1, 2 e 3, respectivamente, corresponderam às maiores porcentagens de plântulas normais obtidas no teste de envelhecimento acelerado.

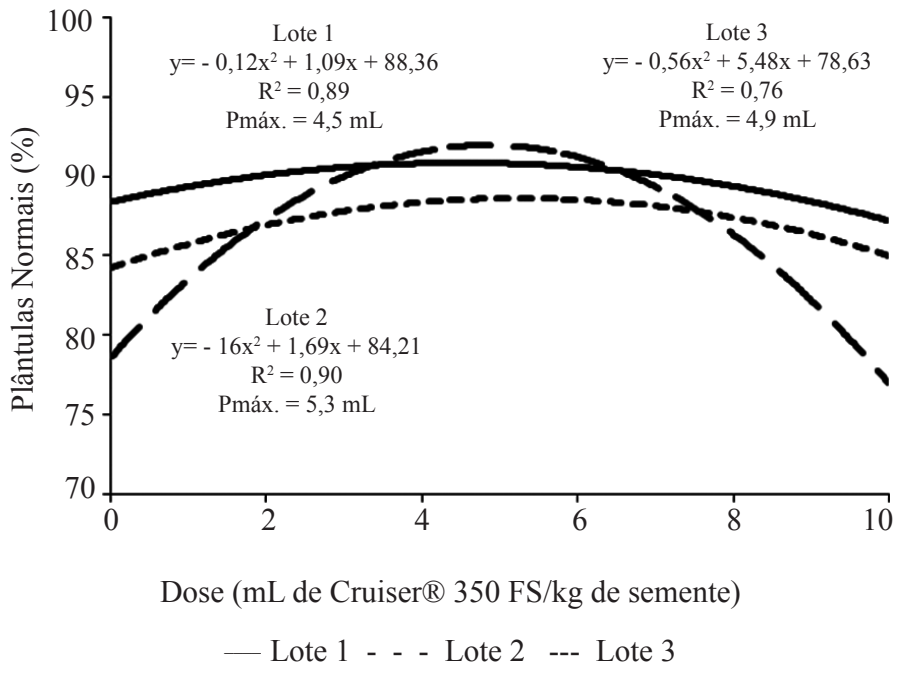

FIGURA 3. Plântulas normais (\%) obtidas no teste de envelhecimento acelerado de três lotes de sementes de algodão, cultivar CD 408, em função da dose de Cruiser ${ }^{\circledR} 350$ FS contendo 35 gramas de tiametoxam por litro.

Ocorreu uma variação positiva entre os tratamentos, que chegou a dezoito pontos percentuais entre as doses zero e 4,9 mL de Cruiser® $350 \mathrm{FS} / \mathrm{kg}$ de semente, nas sementes do lote 3. Essa diferença entre a dose zero e a dose de Cruiser ${ }^{\circledR} 350 \mathrm{FS}$, contendo tiametoxam, que apresentou maior resposta pode ser explicada devido ao fato do tiametoxam movimentar-se através das células da planta e ativar várias reações fisiológicas, como a expressão de proteínas funcionais relacionadas aos mecanismos de defesa da planta contra fatores de estresse como secas, elevadas temperaturas, efeitos tóxicos, entre outros, aumentando a produtividade, área foliar e comprimento radicular, conforme constatado em sementes de soja por Tavares e Castro (2005).

Conforme a Figura 4, as sementes tratadas com Cruiser ${ }^{\circledR} 350$ FS, contendo tiametoxam apresentaram comportamento diferente quanto ao comprimento do sistema radicular em relação às não tratadas. $\mathrm{O}$ comprimento radicular apresentou um ponto de máximo nas doses de 5,2 e 7,3 mL de Cruiser ${ }^{\circledR} 350 \mathrm{FS} / \mathrm{kg}$ de semente, dependendo do lote. Após atingir esse ponto ocorre um decréscimo no comprimento radicular à medida que se aumenta a dose do produto comercial. Para o lote 1, uma dose de 7,3 mL de Cruiser ${ }^{\circledR} 350 \mathrm{FS} / \mathrm{kg}$ de semente, pode aumentar em até $2,0 \mathrm{~cm}$ o comprimento das raízes, comparativamente às sementes que não receberam tratamento. 


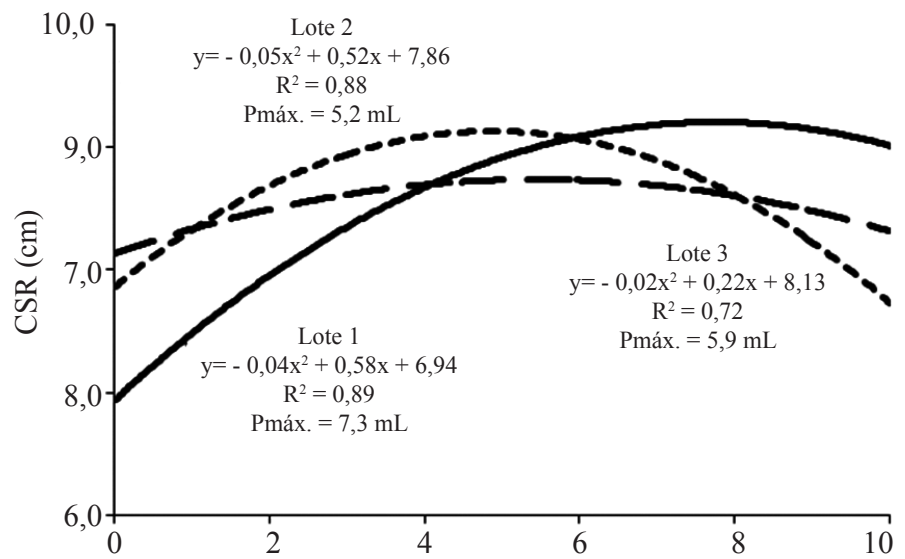

Dose (mL de Cruiser® $350 \mathrm{FS} / \mathrm{kg}$ de semente)

— Lote 1 - - Lote 2 --- Lote 3

FIGURA 4. Comprimento do sistema radicular (CSR) de três lotes de sementes de algodão, cultivar CD 408, em função da dose de Cruiser ${ }^{\circledR} 350$ FS contendo 35 gramas de tiametoxam por litro.

Na Figura 5 constata-se que as plântulas tratadas com as doses de 6 a $8 \mathrm{~mL}$ de Cruiser ${ }^{\circledR} 350 \mathrm{FS} / \mathrm{kg}$ de semente apresentaram maior comprimento do sistema radicular relativamente às demais doses.

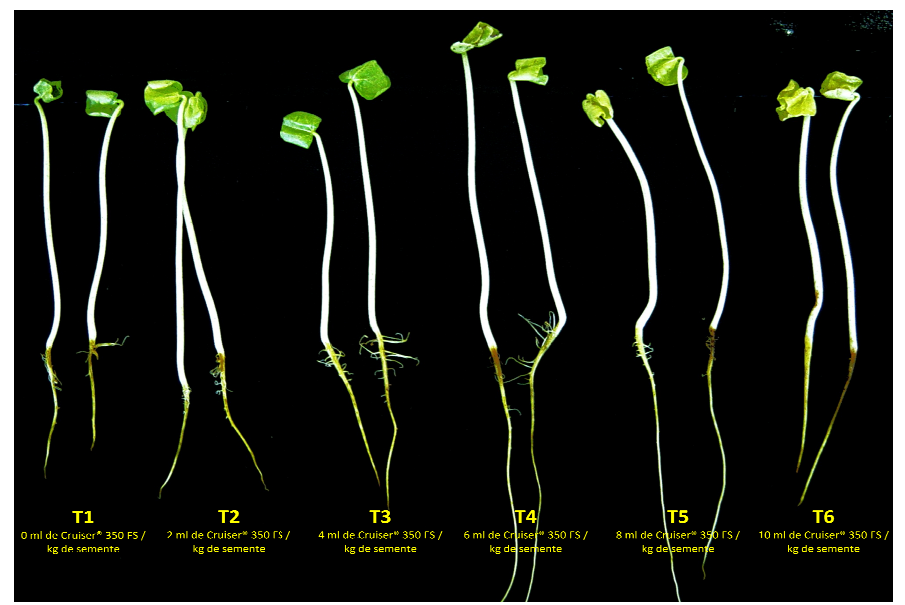

FIGURA 5. Comprimento do sistema radicular, cultivar CD 408, lote 3 , em função da dose de Cruiser ${ }^{\circledR} 350$ FS contendo 35 gramas de tiametoxam por litro.

Observou-se resposta quadrática para massa de matéria seca de raizà aplicação de Cruiser ${ }^{\circledR} 350 \mathrm{FS}$, contendo tiametoxam, com ponto de máxima resposta estimada de 5
$\mathrm{mL}$ de Cruiser ${ }^{\circledR} 350 \mathrm{FS} / \mathrm{kg}$ de semente, para os três lotes (Figura 6). O tratamento com $6 \mathrm{~mL}$ de Cruiser® $350 \mathrm{FS} / \mathrm{kg}$ de semente, contendo tiametoxam, quando comparado com sementes não tratadas, determinou aumento correspondente a $20 \%$, ou seja, aumentou a massa de matéria seca das raízes em até 0,034 gramas/15 plantas em relação às sementes não tratadas.

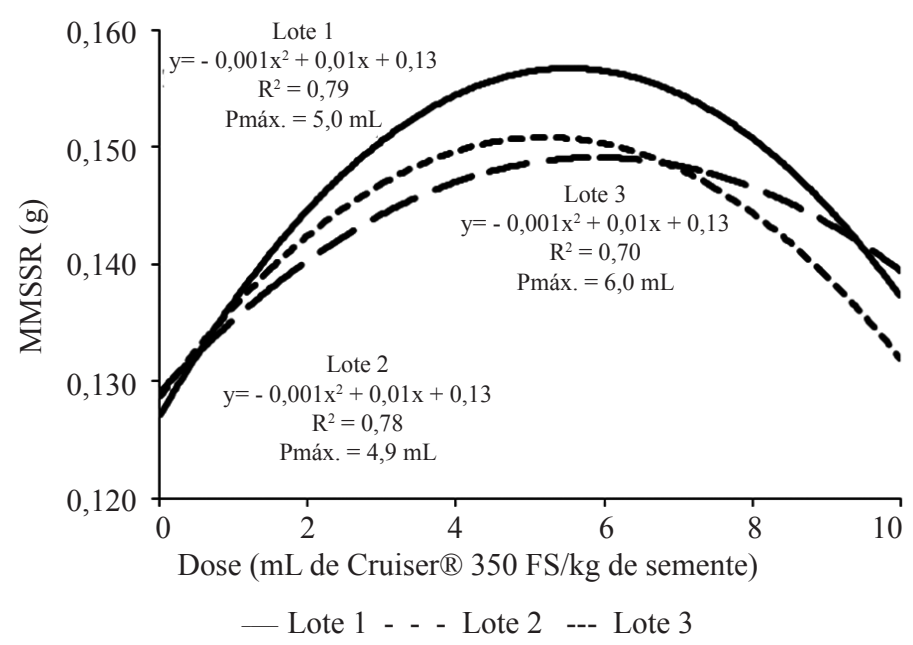

FIGURA 6. Massa de matéria seca do sistema radicular (MMSSR) de três lotes de sementes de algodão, cultivar CD 408, em função da dose de Cruiser ${ }^{\circledR} 350$ FS contendo 35 gramas de tiametoxam por litro.

Essa tendência do tiametoxam em aumentar a massa e o comprimento do sistema radicular corrobora o efeito verificado por Tavares et al. (2007) na cultura da soja. Existe na literatura, a hipótese de que o tiametoxam aumente a absorção de água e a resistência estomática, melhorando o equilíbrio hídrico da planta, tolerando melhor os déficits hídricos (Castro, 2006b). Conforme constatado em soja, o desenvolvimento das raízes aumenta a absorção de nutrientes minerais elevando a área foliar e favorecendo a expressão do vigor das plantas (Tavares e Castro, 2005).

O índice de velocidade de emergência (IVE) apresentou ajuste quadrático em relação ao efeito da dose de Cruiser ${ }^{\circledR}$ $350 \mathrm{FS}$, contendo tiametoxam, e verificou-se que a partir da dose zero, houve aumento nos valores do IVE nos tratamentos contendo tiametoxam. Porém, percebe-se também que o IVE tendeu a decrescer com o aumento da dose acima de $6 \mathrm{~mL}$ de Cruiser ${ }^{\circledR} 350 \mathrm{FS} / \mathrm{kg}$ de semente. Assim, verifica-se que a partir da dose zero, a curva possui tendência crescente, chegando a um ponto máximo alcançado quando a dose 
atinge 4,5 a $6,0 \mathrm{~mL}$ de Cruiser ${ }^{\circledR} 350 \mathrm{FS} / \mathrm{kg}$ de semente, dependendo do lote. Após atingir esse ponto, o IVE começa a apresentar diminuição, conforme aumenta a dose do produto (Figura 7).

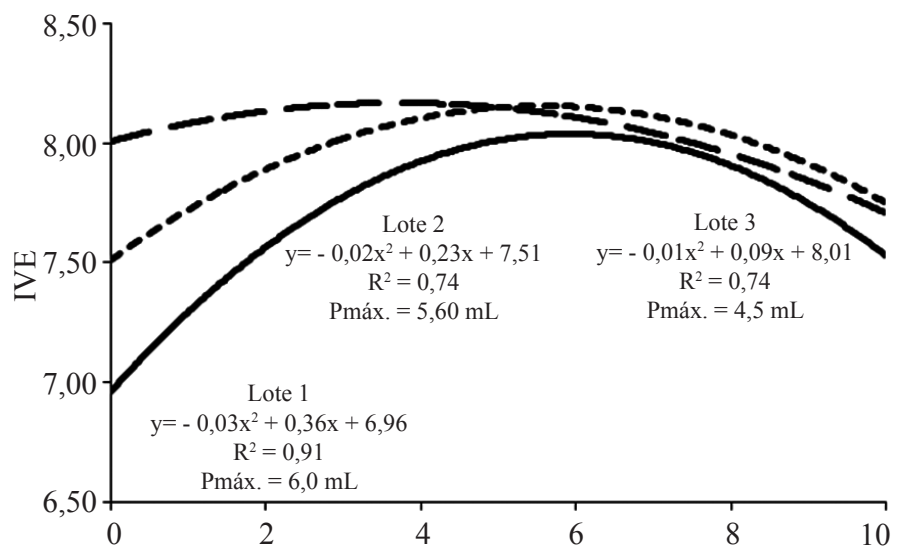

Dose (mL de Cruiser ${ }^{\circledR} 350 \mathrm{FS} / \mathrm{kg}$ de semente)

- Lote 1 - - - Lote 2 --- Lote 3

FIGURA 7. Índice de velocidade de emergência (IVE) de três lotes de sementes de algodão, cultivar CD 408, em função da dose de Cruiser ${ }^{\circledR} 350$ FS contendo 35 gramas de tiametoxam por litro.

Uma análise geral dos dados obtidos com a cultivar CD 408 permite afirmar que, para a maioria das avaliações, especialmente nos testes de vigor, maiores acréscimos foram alcançados com a utilização de tiametoxam em sementes de menor qualidade fisiológica. Além disso, a qualidade fisiológica das sementes de algodoeiro foi favorecida pelo tratamento com tiametoxam, com efeitos mais expressivos nas doses compreendidas entre 5 a $7 \mathrm{~mL}$ de Cruiser ${ }^{\circledR} 350$ $\mathrm{FS} / \mathrm{kg}$ de semente (correspondente a faixa de 0,175 a 0,245 g.i.a. de tiametoxam por litro).

\section{CONCLUSÕES}

O tratamento de sementes de algodoeiro com tiametoxam favorece positivamente a qualidade fisiológica das sementes.

As doses de 5,0 a 7,0 $\mathrm{mL}$ de Cruiser ${ }^{\circledR} 350 \mathrm{FS} / \mathrm{kg}$ de semente, que correspondem a faixa compreendida entre 0,175 a 0,245 g.i.a. de tiametoxam por litro, mostraram-se mais eficientes em melhorar o desempenho fisiológico das sementes de algodoeiro.

\section{REFERÊNCIAS}

BRASIL. Ministério da Agricultura e Reforma Agrária. Secretaria Nacional de Defesa Agropecuária. Departamento Nacional de Defesa Vegetal. Coordenação de Laboratório Vegetal. Regras para análise de sementes. Brasília, DF, 1992. 365p.

CALAFIORI, M.H.; BARBIEIRI, A.A. Effects of seed treatment with insecticide on the germination, nutrients, nodulation, yield and pest control in bean (Phaseolus vulgaris L.) culture. Revista Ecossistema, v.26, n.1, p.97104. 2001.

CASTRO, P.R.C.; VIEIRA, E.L. Biorreguladores e bioestimulantes na cultura do milho. In: FANCELLI, A.L.; DOURADO NETO, D. (Ed.). Milho: estratégias para alta produtividade. Piracicaba: ESALQ/USP/LPV, 2003. p.99115.

CASTRO, P.R.C.; PITELLI, A.M.C.M.; PERES, L.E.P. Avaliação do crescimento da raiz e parte aérea de plântulas de tomateiro MT, DGT E BRT germinadas em diferentes concentrações do inseticida thiametoxan. In ESCOLA SUPERIOR DE AGRICULTURA "LUIZ DE QUEIROZ". Relatório técnico ESALQ/Syngenta. 2005. p.14-25.

CASTRO, P.R.C. Agroquímicos de controle hormonal na agricultura tropical. Piracicaba: ESALQ, 2006a. 46p. (Série Produtor Rural, 32).

CASTRO, P.R.C. Bioativador estimula produção de hormônios responsáveis pelo crescimento da soja. Agência USP de noticias. São Paulo, 29 agosto 2006. Disponível em: $\quad<$ http://www.usp.br/agen/repgs/2006/pags/169.htm>. Acesso em: 15 outubro 2007. 2006b.

CASTRO; P.R.C.; PEREIRA, M. Bioativadores na agricultura. In: GAZZONI, D.L. (Ed.). Tiametoxam. uma revolução na agricultura brasileira. São Paulo: Vozes, 2008. p.101-108.

CATANEO, A.C.; ANDRÉO, Y.; SEIFFERT, M.; BÚFALO. J.; FERREIRA.; L.C. Ação do inseticida Cruiser sobre a germinação do soja em condições de estresse. In CONGRESSO BRASILEIRO DE SOJA, 4., 2006, Resumos... Londrina: Embrapa Soja, 2006. p.90.

DUTRA, A.S.; CASTRO, J.R. Qualidade da semente de 
algodão herbáceo em função do grau de umidade e condição de armazenamento na sua conservação. In: CONGRESSO BRASILEIRO DE ALGODÃO, 1., 1997, Fortaleza, Anais... Campina Grande: EMBRAPA-CNPA, 1997. p.591-592.

FREITAS, R.A.; DIAS, D.C.F.S.; CECON, P.R.; REIS, M.S. Qualidade fisiológica e sanitária de sementes de algodão durante o armazenamento. Revista Brasileira de Sementes, v.22, n.2, p.94-101, 2000.

GOULART, A.C.P.Efeito do tratamento químico de sementes de algodão (Gossypium hirsutum L.) no controle de fungos causadores de tombamento. Fitopatologia Brasileira, v.13, n.2, p.110, 1998 .

KIKUTI, A.L.P.; OLIVEIRA, J.A.; MEDEIROS FILHO. S.; FRAGA. A.C. Armazenamento e qualidade fisiológica de sementes de algodão submetidas ao condicionamento osmótico Revista Ciência e Agrotecnologia, v.26, n.2, p.439-443, 2002.

LAPOSTA, J.A. Comparação entre métodos para avaliação da qualidade fisiológica de sementes de algodão (Gossypium hirsutum L.). 1991. 61f. Dissertação (Mestrado em Agronomia - Fitotecnia) - Escola Superior de Agricultura de Lavras, Lavras, 1991.

MAGUIRE, J.D. Speed of germination and in selection and evaluation for seedling emergence and vigor.Crop Science, v.2, n.2, p.176-177, 1962.

MARCOS FILHO, J.; CÍCERO, S.M.; SILVA.; W.R. Avaliação da qualidade de sementes. Piracicaba: FEALQ, 1994. 230p.

McDONALD JR, M.B.; PHANEENDRANATH, B.R. A modified accelerated aging vigor test procedure. Journal of Seed Technology, v.3, n.1, p.27-37, 1978.

MEDEIROS FILHO, S.; SILVAS, S.O.; DUTRA, A.S.; TORRES, S.D. Metodologia do teste de germinação em sementes de algodão, com línter e deslintada. Revista
Caatinga, 19, n.1, p.56-60, 2006.

PEREIRA, O.A.P. Tratamento de sementes de milho no Brasil. In: MENTEN, J.O.M. (Ed.). Patógenos em sementes: detecção, danos e controle químico. Piracicaba: FEALQ, 2007. p.271- 279.

REDDY, K.R.; REDDY, V.R.; BAKER, D.N.; McKINION, J.M. Is aldicarb a plant growth regulator. In PLANT GROWTH REGULATION SOCIETY OF AMERICAN ANNUAL MEETING, 17., Proceedings... Saint Paul: Plant Regulation Society of American, 1990. p.79-80.

RIBEIRO, U.P.; PINHO, E.V.R.V.; GUIMARÃES, R.M.; VIANA.; L.S. Determinação do potencial osmótico e do período de embebição utilizados no condicionamento fisiológicodesementes dealgodão. Ciência eAgrotecnologia, v.26, n.5, p.911-917, 2002.

RODRIGUES FILHO, F.S.O. Conservação de sementes de algodoeiro deslintadas por diferentes métodos. Bragantia, v.38, n.11, p.107-113, 1979.

SERCILOTO, C.M. Bioativadores de Plantas. Revista Cultivar HF, v.13, p.20-21, 2002.

TAVARES, S.; CASTRO, P.R.C.; RIBEIRO, R.V.; ARAMAKI.; P.H. Avaliação dos efeitos fisiológicos de tiametoxam no tratamento de sementes de soja. Revista de Agricultura, v.82, p.47-54, 2007.

TAVARES, S.; CASTRO, P.R.C. Avaliação dos efeitos fisiológicos de Cruiser 35FS após tratamento de sementes de soja. In: ESCOLA SUPERIOR DE AGRICULTURA "LUIZ DE QUEIROZ". Relatório técnico ESALQ/Syngenta, 2005. p.1-13.

ZANQUETA, R.; FURLAN JR, E.; SILVA, N.M da; CARVALHO, L.H.; BARBOSA, M.R. Aplicação de regulador de crescimento para o cultivar de algodão (Gossypium hirsutum L. s. latifolium, Hutch.) IAC 20 RR e ITA 96, em diferentes densidades populacionais. In: CONGRESSO BRASILEIRO DE ALGODÃO, 2., Ribeirão Preto - SP. 1999. Anais... Ribeirão Preto, 2001 ,p.439-441. 